\title{
Steady current induced seabed scour around a vibrating pipeline
}

\author{
Fu-Ping Gao*, Bing Yang, Ying-Xiang Wu, Shu-Ming Yan \\ Institute of Mechanics, Chinese Academy of Sciences, Beijing 100080, China
}

Received 6 September 2006; received in revised form 3 December 2006; accepted 13 January 2007

Available online 26 March 2007

\begin{abstract}
Most of the existing researches either focus on vortex-induced vibrations (VIVs) of a pipeline near a rigid boundary, or on seabed scour around a fixed pipeline. In this study, the coupling effects between pipeline vibration and sand scour are investigated experimentally. Experimental results indicate that there often exist two phases in the process of sand scouring around the pipeline with an initial embedment, i.e. Phase I: scour beneath pipe without VIV, and Phase II: scour with VIV of pipe. During Phase II, the amplitude of pipe vibration gets larger and its frequency gets smaller while the sand beneath the pipe is being scoured, and finally the pipe vibration and sand scour get into an equilibrium state. This indicates that sand scouring has an influence upon not only the amplitude of pipe vibration but also its frequency. Moreover, the equilibrium scour depth decreases with increasing initial gap-to-diameter ratio for both the fixed pipes and vibrating pipes. For a given value of initial gapto-diameter ratio $\left(e_{0} / D\right)$, the vibrating pipe may induce a deeper scour hole than the fixed pipe in the examined range of initial gap-to-diameter ratios $\left(-0.25<e_{0} / D<0.75\right)$.
\end{abstract}

(C) 2007 Elsevier Ltd. All rights reserved.

Keywords: Submarine pipeline; Scour; Sandy seabed; Current; Vortex-induced vibration

\section{Introduction}

When a submarine pipeline is laid upon seafloor and subjected to ocean currents, there exists a complex interaction between current, pipeline and soil. Pipeline spans may exist in some locations due to the unevenness of the seafloor and (or) soil erosion around the pipeline. When exposed to currents or other hydrodynamic loads, such pipeline spans may experience vortex-induced vibration (VIV), which has been widely recognized as one of the main causes for fatigue damage to pipelines [12]. Therefore, it is highly essential to analyze the dynamic responses of a submarine pipeline near the seabed in severe ocean environments for the proper design of submarine pipelines.

During recent decades, the dynamic interaction between ocean currents/waves, pipelines and the seabed has received wide interest from submarine pipeline designers and researchers [2,7,12,21]. Numerous experiments on currentinduced vibrations of a pipeline have shown that, when the vortex shedding frequency brackets the natural frequency of an

\footnotetext{
* Corresponding author. Tel.: +8610 62618499; fax: +861062561284.

E-mail address: fpgao@imech.ac.cn (F.-P. Gao).
}

elastic or elastically mounted rigid cylinder, the cylinder takes control of the shedding frequency in an apparent violation of the Strouhal law. Then the vortex-shedding and pipeline oscillation collapses into a single frequency, which is well known as the 'lock-in' phenomenon [15]. A few experimental results for vibrating cylinders with two degrees of freedom indicated that the amplitudes of cross-stream vibration are usually much larger than those of in-line vibration [3]. For the above reasons, many researchers paid their attentions mostly to the crossstream vibrations of cylinders, such as the work by Khalak and Williamson [14] and Govardhan and Williamson [9]. However, the aforementioned researches focus on pipeline vibrations near a rigid boundary or under wall-free conditions where the soil scour was not involved.

At present, the most reliable approach to predicting scour around an offshore structure is to conduct model tests simulating the real conditions [2]. Recently, much effort has also been devoted on the two-dimensional soil scour around fixed pipelines in currents, such as the work done by Hansen et al. [11], Sumer et al. [17], and Chiew [5]. The scour in the middle of the suspended span of a pipeline can be considered as a two-dimensional process. The scour around the span shoulders is definitely a three-dimensional one. As 


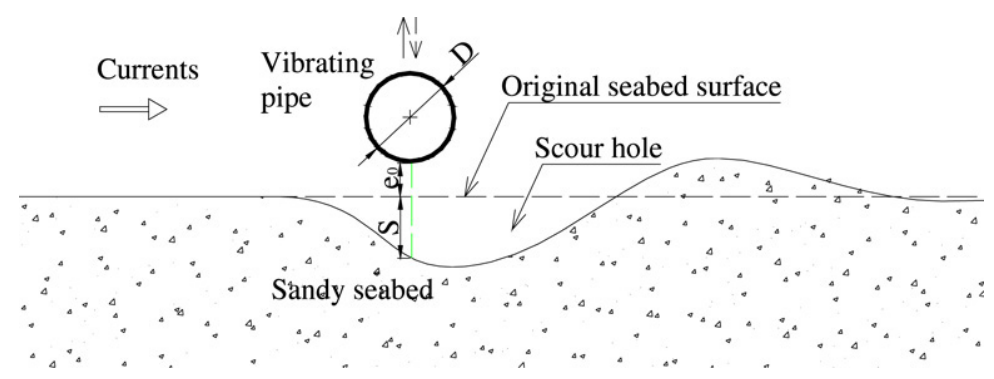

Fig. 1. Sketch of sand scouring around a vibrating pipeline.

for the three-dimensional scour case, various scenarios may occur in a real-life situation, depending on the conditions of flow, soil and pipe. For example, the pipeline may sink at span shoulders and sometime be buried by the backfilling soil [19]. The researches on seabed scour around coastal structures have been summarized by Sumer and Fredsoe [21]. It should be noted that a pipe with an initial embedment is not always scoured to have itself suspended; it may also lose on-bottom stability when the lateral soil resistance cannot balance the hydrodynamic loads $[7,8]$.

Most of the previous researches either concentrate on soil scour around fixed pipelines, or on the vortex-induced vibrations of a pipeline near a rigid boundary, such as the work by Jacobsen et al. [13] and Yang et al. [23]. Unlike wallfree cylinders, a cylinder in the vicinity of a rigid boundary will not shed regular vortices but still vibrate, as observed by Jacobsen et al. [13]. In actual situations, pipeline vibration and soil scour are always coupled. Until now, however, studies on the interaction between a vibrating pipe and soil scour are scarce $[16,18]$. In the work by Sumer et al. [18], two kinds of experiment were conducted. In the experiments for investigating the influence of transverse vibration of pipeline on sand scour, the test pipe was free to vibrate vertically while soil scour was taking place from the outset of test; however, in their experiments for investigating the influence of scour on pipeline vibration, the pipe was initially maintained stationary for $30 \mathrm{~min}$ at a given flow speed during which scour reached it equilibrium state, and the pipe was subsequently released to vibrate freely above the scour hole. Shen et al. [16] primarily investigated the cross-stream and in-line vibrations of a pipeline near erodible sands. The previous studies have indicated that pipe vibration has influences on soil scour and vice versa. Nevertheless, due to the complexity of the physical phenomena, the underlying mechanism of the dynamic interaction between pipe vibration and soil scour has not yet been well understood.

In this study, the current-induced sand scour around a vibrating pipeline was simulated experimentally with a new hydro-elastic facility. Based on similarity analyses, a series of tests was conducted to further investigate the mechanism of the coupling effects between pipe vibration and sand scour.

\section{Dimensionless analyses on current-pipeline-soil interac- tion}

When a submarine pipeline is laid upon a sandy seabed and exposed to steady currents, there exists a dynamic interaction between currents, pipeline and sand. Local scour may be coupled with the pipe vibration under the influence of currents, as illustrated in Fig. 1.

In this study, a sandy seabed is considered. The equilibrium scour depth beneath a vibrating pipeline $(S)$ in a steady current is mainly dependent on the following characteristic parameters of flow, pipe and seabed, i.e.

$S=f\left(U, v, g, \rho, \rho_{s}, d_{s}, D_{r}, e_{0}, D, m, f_{n}, \xi, k_{s} \ldots\right)$

where $U$ is the flow velocity, which is often taken as the undisturbed flow velocity at the center of pipeline; $v$ is the kinetic viscosity of fluid; $g$ is the gravitational acceleration; $\rho$ is the mass density of fluid; $d_{s}$ is the diameter of sand particles, which is usually chosen as the mean diameter $\left(d_{50}\right) ; D_{r}$ is the relative density of sand; $D$ is the outer diameter of pipeline; $m$ is the mass of a pipeline per meter; $f_{n}$ is the natural frequency of the pipeline in still fluid; $\xi$ is the structural damping factor; $k_{s}$ is the roughness of pipeline surface; $e_{0}$ is the initial gap between the pipeline and the seabed.

According to dimensional analysis for Eq. (1), the dimensionless equilibrium scour depth $(S / D)$ beneath a vibrating pipeline can be determined by a group of independent dimensionless parameters as

$S / D=f\left(V_{r}, e_{0} / D, \theta, D_{r}, G_{s}, R e, m^{*}, K, d_{s} / D, k_{s} / D \ldots\right)$

where the reduced velocity $V_{r}$ is defined as

$V_{r}=U / D f_{n}$

which is for describing the widths of the lock-in range of vortex-induced vibrations of the pipeline; $e_{0} / D$ is the dimensionless initial gap between the pipeline bottom and the seabed surface; the Shields parameter $(\theta)$ is defined as

$\theta=U_{f}^{2} /\left(G_{s}-1\right) g d_{s}$

which governs the sediment transport, where the undisturbed bed shear velocity $U_{f}$ can be calculated with the Colebrook-White formula, i.e. $U / U_{f}=8.6+2.5 \ln \left(D / 2 k_{b}\right)$, in which $k_{b}$ is the roughness of the seabed (usually taken as $2.5 d_{s}$ ) [19]; The sand relative density $D_{r}$ is defined as

$D_{r}=\frac{e_{\max }-e}{e_{\max }-e_{\min }}$

which is used to express the relationship between the in situ void ratio $(e)$ and the limiting values $e_{\max }$ and $e_{\min }$ of the sand 
sample [6]; $G_{s}=\rho_{s} / \rho$ is the specific gravity of sand particles, which is taken as approximately 2.65 for standard sand; the Reynolds number is defined as

$\operatorname{Re}=U D / \nu$

which is the ratio of inertia force to viscous force;

$m^{*}=4 m / \pi \rho D^{2}$

is the pipeline mass ratio;

$K=4\left(m+m_{a}\right) \xi / \pi \rho D^{2}$

is the stability parameter of a vibrating pipeline, where $m_{a}$ is the added mass, $m_{a}=C_{A} m_{d}$ ( $m_{d}$ is the displaced fluid mass per meter, $C_{A}$ is the potential added-mass coefficient, $C_{A}=1.0$ and $m_{d}=\pi \rho D^{2} / 4$ for a cylinder); $d_{S} / D$ is the dimensionless diameter of sand particles; $k_{s} / D$ is the relative roughness of the pipeline.

The above similarity analyses are for sand scour around a vibrating pipeline. When one examines the scour depth around a fixed pipeline, some parameters related to vortex-induced vibration of pipeline should not be involved, i.e.

$S / D=f\left(e_{0} / D, \theta, D_{r}, G_{s}, R e, d_{s} / D, k_{s} / D \ldots\right)$

for a fixed pipe.

\section{Experimental setup}

\subsection{A hydro-elastic facility for simulating current-pipe-soil interaction}

A hydro-elastic facility was designed and constructed for the present experimental investigation, which is in conjunction with a water flow channel, as illustrated in Fig. 2. The water flow channel is $0.5 \mathrm{~m}$ wide, $0.6 \mathrm{~m}$ high and $19 \mathrm{~m}$ long, and is capable of generating steady currents with velocity up to approximately $0.4 \mathrm{~m} / \mathrm{s}$. The water depth is $0.4 \mathrm{~m}$. The test pipe was attached to the supporting frame by two connecting poles, two sliding poles and two sets of springs. The sliding poles can move along the four runners, which are connected to the two localizers by four bearings. Only transverse pipe vibration was simulated in this study. A laser displacement transducer was employed for the non-contact measurement of the vertical displacement of the vibrating pipeline. Concurrently, the time development of scour depth was recorded with a digital camera. After the flow was stopped when the scour reached its equilibrium stage, the longitudinal scour profile was measured with a depth probe, which was installed upon and could slide along the two sidewalls of the flume. One of the main research interests of this study is to examine the effects of the proximity of the pipeline to the seabed upon the dynamic responses of the pipeline and upon the scour depth. As such, the gap between the test pipe and the sand surface was designed to be varied easily with two vertical slotted portions on the supporting frame (see Fig. 2).
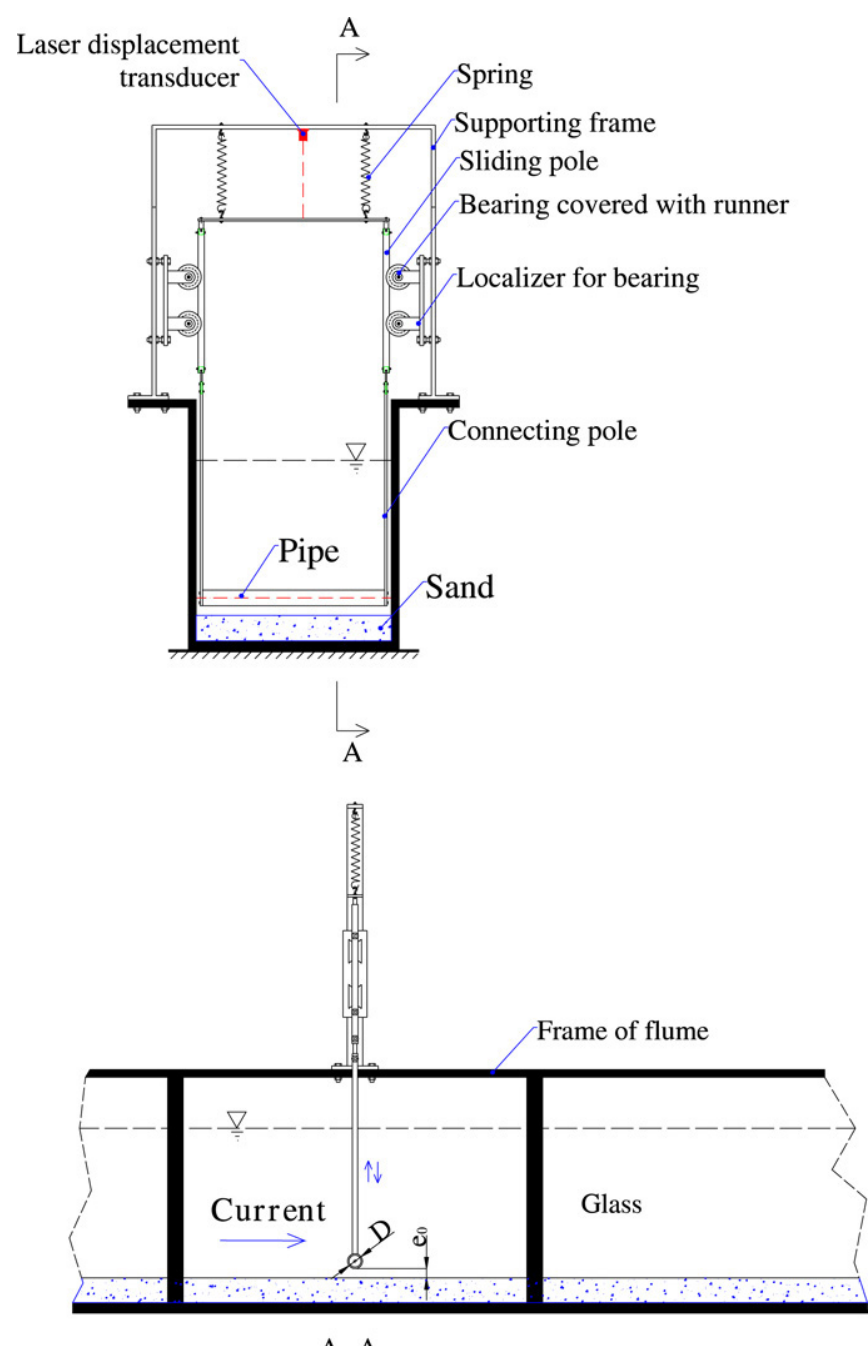

A--A

Fig. 2. Schematic diagram of experimental apparatus for current-pipeline-soil interaction.

\subsection{Test conditions and procedure}

Two types of pipeline were taken into account in the experiments, i.e. Type I: fixed pipes, and Type II: vibrating pipes. For the vibrating pipe, its mass, natural frequency and structural damping factor are kept constant, i.e. $m=$ $3.10 \mathrm{~kg} / \mathrm{m}, f_{n}=1.22 \mathrm{~Hz}, \zeta=0.0186$. Note that the natural frequency of the pipeline system $f_{n}$ and structural damping factor $\zeta$ are determined by analyzing the records of the displacements of pipe, which was given a prescribed vertical displacement and then released in still water. The test pipe is $0.032 \mathrm{~m}$ in diameter, $0.47 \mathrm{~m}$ in length. Only smooth pipes are considered in this study, i.e. $k_{s} / D \approx 0$.

In order to make meaningful comparisons of the responses of aforementioned two types of pipes, only one kind of sandy seabed was adopted, whose grain size distribution is shown in Fig. 3. Its mean particle diameter $d_{50}=0.38 \mathrm{~mm}$, and relative density $D_{r}=0.66$, indicating that the sand sample is a medium-dense one.

The velocity of steady flow in the experiments is $U=$ $0.255 \mathrm{~m} / \mathrm{s}$. The corresponding dimensionless parameters are $V_{r}=6.53, m^{*}=3.86, K=0.09, \theta=0.039, R e \approx 0.82 \times 10^{4}$. 


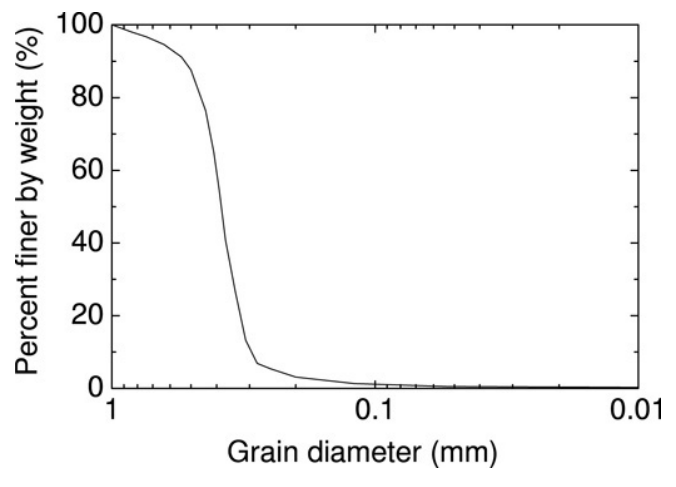

Fig. 3. Grain size distribution curves of the test sand.

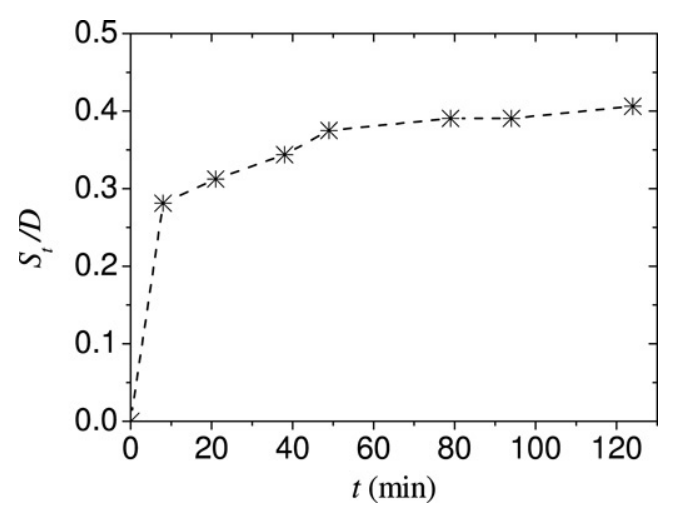

Fig. 4. The development of scour depth beneath pipeline with time for a fixed pipe ( $D=0.032 \mathrm{~m}, e_{0} / D=0, U=0.255 \mathrm{~m} / \mathrm{s}, \theta=0.039$, medium-dense sand: $\left.d_{50}=0.38 \mathrm{~mm}, D_{r}=0.66\right)$.

In the experiments, $R e$ is of the order of $10^{4}$, being in the subcritical flow range, whereas in the fields, $R e$ is of the order of $10^{5}$ or more. Nevertheless, the effects of Reynolds number on the vortex shedding are negligible, when high Reynolds number and marine-roughened real-life pipelines are considered [1,17].

\section{Experimental results and analyses}

\subsection{Sand scour beneath a fixed pipe with various $e_{0} / D$}

The flow disturbance by the presence of pipeline may induce local scour in the proximity of the pipeline. A typical time development of scour depth $\left(S_{t}\right)$ below a fixed pipeline is shown in Fig. 4. It can be seen from the figure that the sand scouring speed gets slower and slower with time. When the scouring time is long enough (e.g. $120 \mathrm{~min}$, see Fig. 4), an equilibrium state is finally reached.

In this study, the sand scour around a pipe embedded in seabed is also involved. In order to have a knowledge of the effects of initial gap-to-diameter ratio $\left(e_{0} / D\right)$ on the scour depth, three values of gap-to-diameter ratio are chosen in the tests, i.e. $e_{0} / D=0.2,0,-0.25$. The other test conditions are kept unchanged, i.e. $D=0.032 \mathrm{~m}, U=0.255 \mathrm{~m} / \mathrm{s}, \theta=0.039$, $d_{50}=0.38 \mathrm{~mm}, D_{r}=0.66$.

For the pipe with an initial embedment, the currents with a certain velocity may induce sand scour beneath the pipe, and the pipe is finally suspended with a gap between the pipe bottom and the surface of the scoured seabed, as illustrated in Fig. 5.

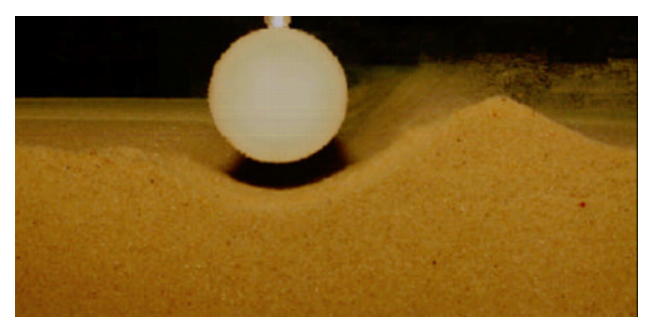

Fig. 5. Scour underneath a pipe with an initial embedment.

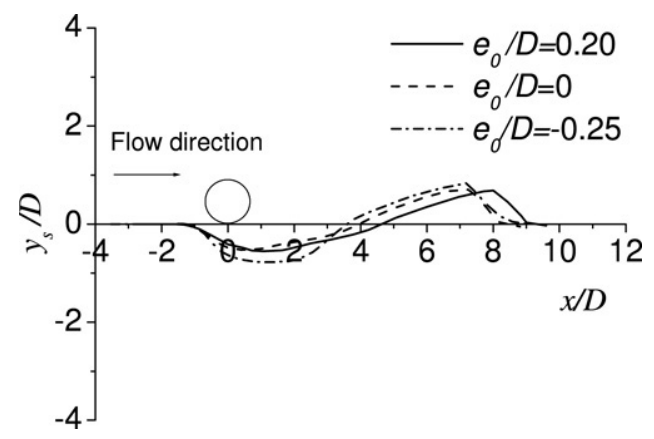

Fig. 6. Equilibrium scour profiles around a fixed pipeline with various gap-todiameter ratios $(D=0.032 \mathrm{~m}, U=0.255 \mathrm{~m} / \mathrm{s}, \theta=0.039$, medium-dense sand: $\left.d_{50}=0.38 \mathrm{~mm}, D_{r}=0.66\right)$.

After that, the soil scour was kept continuing until it reached an equilibrium state. The sand scour profiles around a fixed pipeline were measured with a depth probe. The equilibrium scour profile is characterized as a steep slop at the upstream side of the test pipe and a gentle slope at the downstream side (see Fig. 6). It is also indicated in Fig. 6 that the equilibrium scour depth increases with the decrease of initial gap-to-diameter ratio.

\subsection{Sand scour around vibrating pipes}

\subsubsection{Coupling between pipe vibration and sand scour}

In the aforementioned experiments, the sand scour around stationary pipes was modeled. In reality, however, soil scour is prone to coupling with the vortex-induced vibrations of the pipeline. Therefore, it is crucial to investigate the coupling effects between them.

In this subsection, the dynamic interaction between the pipe vibration induced by currents and the sand scour around the pipe will be further investigated. Two cases of pipeline are considered, i.e. Case I: a pipeline with an initial gap to the seabed $\left(e_{0} / D \geq 0\right)$, and Case II: a pipeline with initial embedment in the seabed $\left(e_{0} / D<0\right)$.

Case I: A pipeline with an initial gap to seabed $\left(e_{0} / D \geq 0\right)$

The time development of the displacement of a vibrating pipe and the change of scour depth with time are shown in Fig. 7(a) and in Fig. 7(b), respectively. It is indicated from the two figures that pipe vibration and sand scour affect each other. For the case of positive $e_{0} / D$, i.e. the vibrating pipe with an initial gap between pipe wall and seabed (e.g. $e / D=$ $0.75)$, the dimensionless equilibrium scour depth $(S / D=0.82$, see Fig. 7(b)) is even higher than that for a fixed pipe with $e_{0} / D=0(S / D=0.41$, see Fig. 4). It is also found that the 

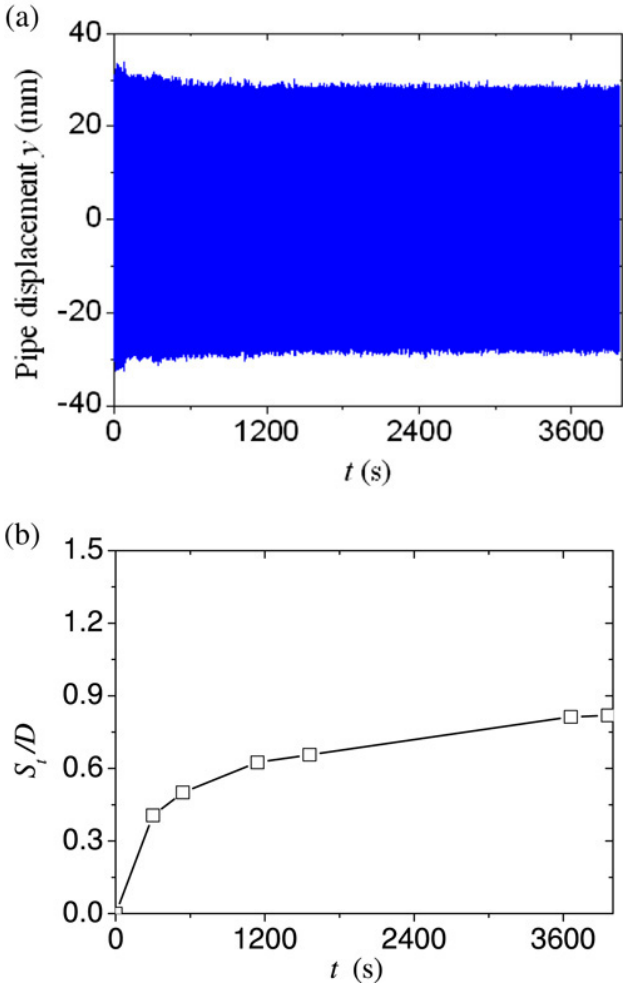

Fig. 7. Time development of pipe vibration and sand scour beneath pipe: (a) Pipe vibration, (b) Sand scour $\left(D=0.032 \mathrm{~m}, e_{0} / D=0.75, m^{*}=3.86\right.$, $f_{n}=1.22 \mathrm{~Hz}, K=0.09, V_{r}=6.53, \theta=0.039$, medium-dense sand: $\left.d_{50}=0.38 \mathrm{~mm}, D_{r}=0.66\right)$.

scour process has some influence on the vibration amplitude, especially at the early stage of sand scouring: the amplitude of pipe vibration gets slightly smaller with the development of sand scouring (see Fig. 7).

Case II: A pipeline with an initial embedment in the seabed $\left(e_{0} / D<0\right)$

In the field, pipelines are installed upon the seabed with some initial embedment (i.e. $e_{0} / D$ is negative) at most locations. The whole process of the dynamic interaction between pipe vibration and sand scour for the case of negative $e_{0} / D$ was physically modeled in our experiments.

The Fig. 8(a) and (b) show the recorded pipe displacement and scour depth, respectively. As illustrated in Fig. 8, there exist two phases during the process of sand scouring for a pipe with initial embedment (e.g. $e_{0} / D=-0.25$ ):

- Phase I: Scour beneath pipe without VIV

At certain values of flow velocity (e.g. $U=0.255$ in our tests), the sand beneath pipe would be scoured, which made the test pipe to be suspended with a gap emerging between the pipe bottom and the surface of the scour hole (see Fig. 5). The occurrence of scour beneath the test pipe was a rapid process compared with the whole scouring course, the mechanism of which has been analyzed in the view of soil piping failure [4,20,22]. Following the occurrence of soil scour beneath the pipe, the scour depth increased with time for a period, during which the pipe vibration was nearly imperceptible, as shown in Fig. 8(a). Vortex shedding
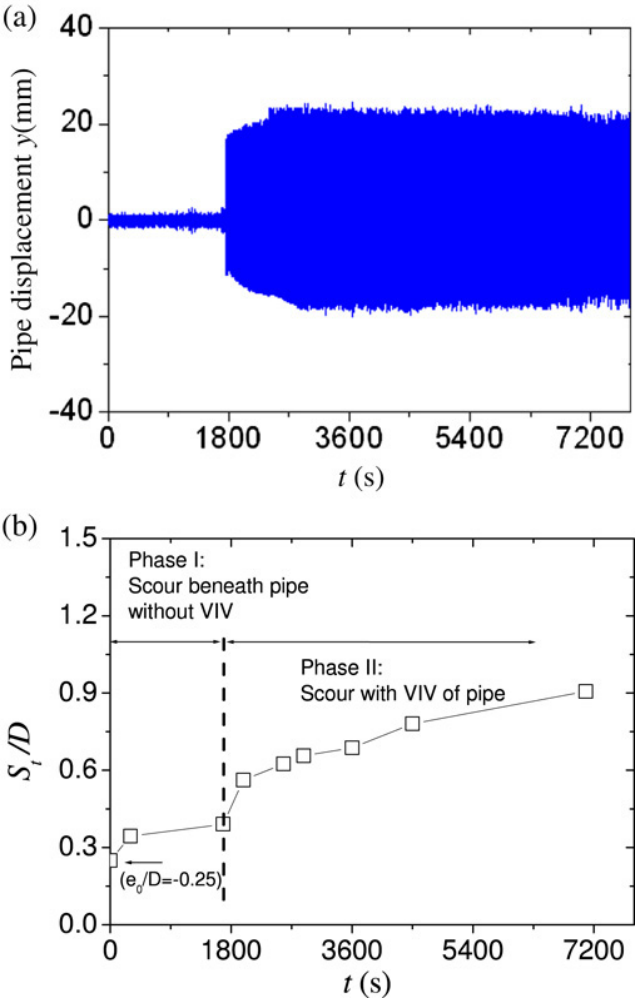

Fig. 8. Time development of pipe vibration and sand scour for a pipe with an initial embedment: (a) Pipe vibration, (b) Sand scour $(D=0.032 \mathrm{~m}$, $e_{0} / D=-0.25, m^{*}=3.86, f_{n}=1.22 \mathrm{~Hz}, K=0.09, V_{r}=6.53, \theta=0.039$, medium-dense sand: $\left.d_{50}=0.38 \mathrm{~mm}, D_{r}=0.66\right)$.

was sharply suppressed for gap-to-diameter ratios lower than a certain value, which has been observed by various researchers [10].

\section{- Phase II: Scour with VIV of pipe}

When the scour depth beneath the pipe became large enough (e.g. $\left(S_{t}+e_{0}\right) / D=0.14$, see Fig. 8(b)), the suppression of wall proximity on vortex shedding was relieved. The strong dynamic interaction between current, pipe and seabed was observed in the experiments: the scour depth becomes even larger; meanwhile, the amplitude of the pipe vibration also gets bigger, and finally the pipe vibration and sand scour get into an equilibrium state, as shown in Fig. 8(a) and (b). Typical time traces of pipeline displacement in the Phase II of sand scouring (i.e. scour with VIV of pipe, see Fig. 8(b)) are given in Fig. 9, and the variation of vibration frequency in the process of sand scouring is plotted in Fig. 10. It is indicated in Figs. 9 and 10 that the frequency of pipeline vibration decreases with the development of sand scouring. Previous experimental results on the influence of plane bed proximity on vortex shedding have confirmed that both the flow velocity and associated vortex shedding frequency increase as the gap between the test cylinder and the bed is reduced [10,23]. Consequently, the sand scouring around the pipeline has much influence upon not only the amplitude of the pipeline vibration, but also its frequency. 
(a)

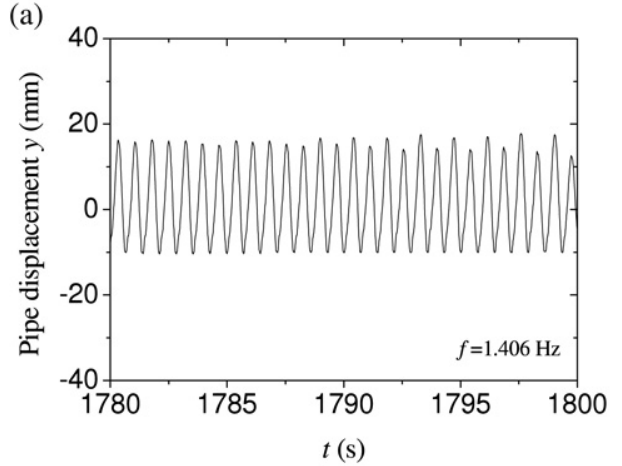

(c)

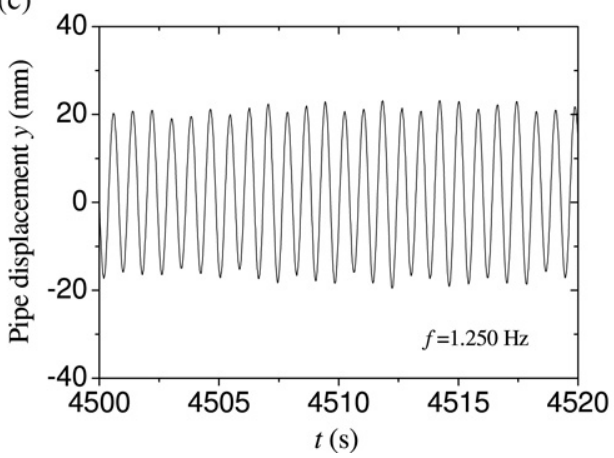

(b)

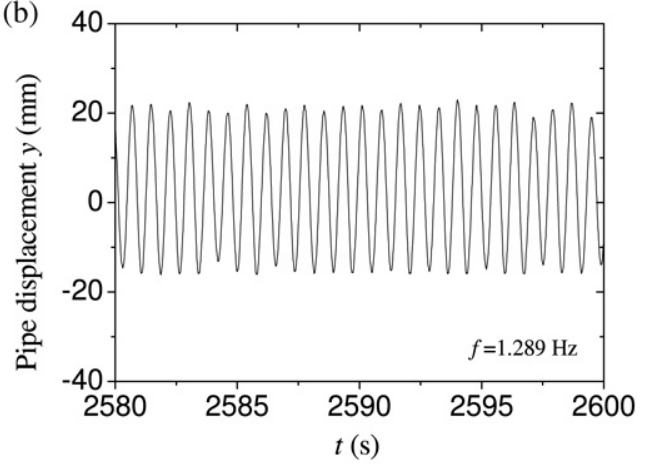

(d)

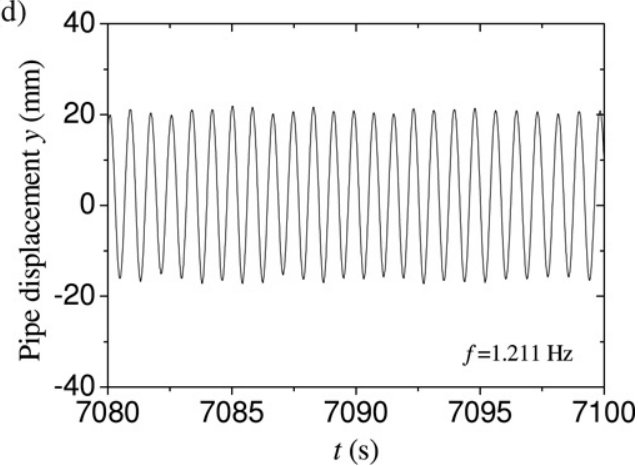

Fig. 9. Typical time traces of pipeline displacement in the process of sand scouring shown in Fig. 8.

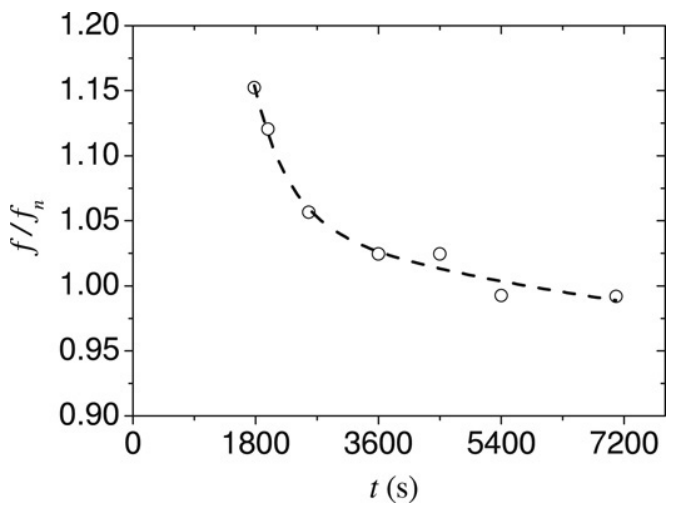

Fig. 10. Variation of frequencies of pipeline vibration in the process of sand scouring shown in Fig. 8.

\subsubsection{Comparison between scour profiles around vibrating pipes with those around fixed pipes}

The influence of the gap-to-diameter ratio upon the sand scour profile is also investigated for the case of vibrating pipes. The equilibrium scour profiles around a vibrating pipeline with various gap-to-diameter ratios, i.e. $e_{0} / D=0.75,0.31,0$ and -0.25 , under the conditions given in Fig. 8 are shown in Fig. 11. As is seen in Fig. 11, the width of the equilibrium scour holes gets larger with the increase of $e_{0} / D$ for the examined range from -0.25 to 0.75 .

Fig. 12 gives a comparison between equilibrium scour profiles around fixed pipes and those around vibrating pipes for $e_{0} / D=0$ and -0.25 . Note that for vibrating pipes with $e_{0} / D=0$ and -0.25 , the recorded vibration amplitudes at equilibrium state (e.g. $t=120 \mathrm{~min}$ ) are about $21.3 \mathrm{~mm}$

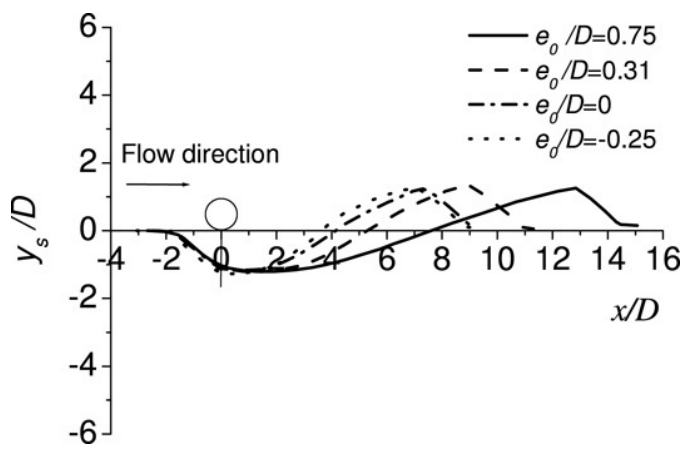

Fig. 11. Equilibrium scour profiles around a vibrating pipeline with various gap-to-diameter ratios under the conditions given in Fig. 7.

and $20.0 \mathrm{~mm}$, respectively, and their vibration frequencies are approximately $1.26 \mathrm{~Hz}$. Fig. 13 gives comparisons of equilibrium scour depth $(S / D)$ versus gap-to-diameter ratio $\left(e_{0} / D\right)$ between the present experimental data with those for the case of vibrating pipes obtained by Sumer et al. [18], and with both the experimental data and the theoretical predictions for the case of fixed pipes by Hansen et al. [11]. Note that there exists some difference between the present test conditions and previous ones, especially in the Shields number. Fig. 13 shows that the present experimental results are comparable with the previous ones. These results indicate that the equilibrium scour depth decreases with increasing initial gap-to-diameter ratio for both fixed pipes and vibrating pipes. The vibrating pipe may induce a deeper scour hole than the fixed pipe for a given value of $e_{0} / D$ in the examined range of gap-to-diameter ratios $\left(-0.25<e_{0} / D<0.75\right)$. 


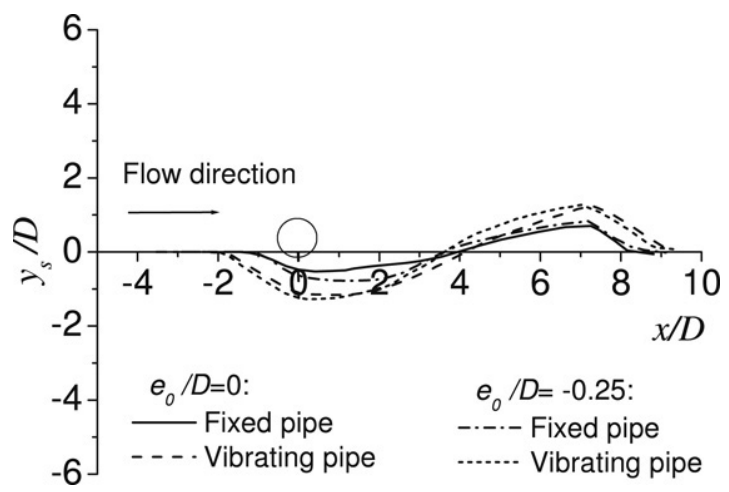

Fig. 12. Comparison between equilibrium scour profiles around fixed pipes and those around vibrating pipes under the conditions given in Fig. 7.

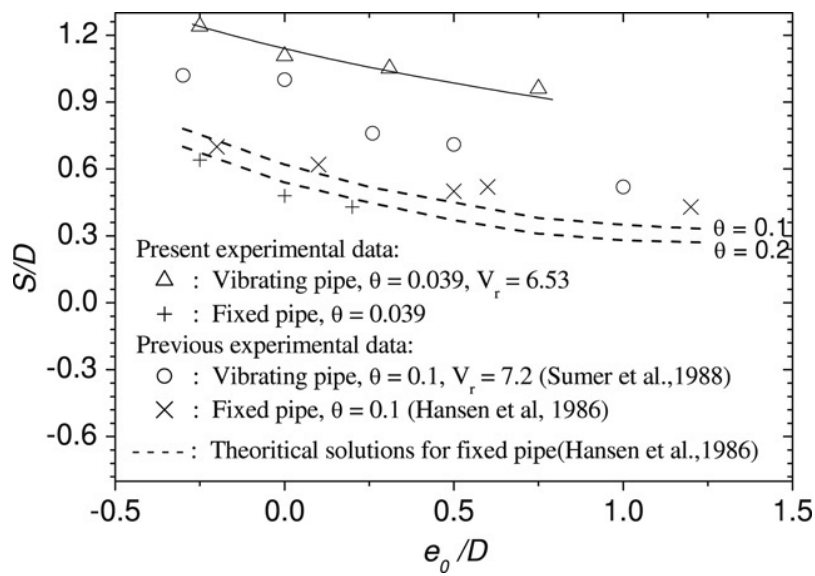

Fig. 13. Equilibrium scour depth versus gap-to-diameter ratio: comparisons with previous data.

\section{Conclusions}

The coupling between pipe vibration and sand scour was physically simulated with a hydro-elastic facility. Based on the results of a series of experiments, the following conclusions can be drawn.

(1) There often exist two phases in the process of sand scouring for a pipeline with an initial small embedment, i.e. Phase I: scour beneath the pipe without VIV, and Phase II: scour with VIV of the pipe. The scour beneath the pipe is not consequentially accompanied with pipe vibration. Only when the scour depth is large enough may vortex-induced vibrations take place. During Phase II, the scour depth becomes even larger due to pipeline vibration; meanwhile, the amplitude of the pipe vibration also gets bigger, and finally the pipe vibration and sand scour get into an equilibrium state.

(2) The sand scour has much influence upon not only the amplitude of pipeline vibration, but also its frequency. The frequency of pipeline vibration decreases slightly with the development of sand scouring.

(3) The equilibrium scour depth decreases with increasing initial gap-to-diameter ratio for both fixed pipes and vibrating pipes. A vibrating pipe in close proximity to an erodible seabed may induce a deeper scour hole than that of fixed pipes for a given value of $e_{0} / D$ in the examined range of gap-to-diameter ratios $\left(-0.25<e_{0} / D<0.75\right)$.

\section{Acknowledgements}

This work is financially supported by National Natural Science Foundation of China (Grant No. 50509022 and Grant No. 10532070) and the Eleventh Five-Year Plan of Chinese Academy of Sciences (Grant No. KJCX2-YW-L02). The helpful discussions with Professor Zhichu Zheng and Professor Zhonghan Shen, and the technical support in the experiments from Senior Engineer Donghui Li are greatly appreciated.

\section{References}

[1] Achenbach E, Heinecke E. On vortex shedding from smooth and rough cylinders in the range of Reynolds numbers $6 \times 10^{3}$ to $5 \times 10^{6}$. Journal of Fluid Mechanics 1981;109:239-51.

[2] Chakrabarti K. Offshore structure modeling. JBW Printers \& Binder Pte. Ltd.; 1994.

[3] Bryndum MB, Bond C, Smitt LW, Tura F, Montesi M. Long free spans exposed to current and waves model test. In: Proceedings of 21st offshore technology conference, OTC 6153. 1989. p. 317-28.

[4] Chiew YM. Mechanics of local scour around submarine pipelines. Journal of Hydraulic Engineering ASCE 1990;118(4):515-29.

[5] Chiew YM. Prediction of maximum scour depth at submarine pipelines. Journal of Hydraulic Engineering ASCE 1991;117:452-66.

[6] Craig RF. Soil mechanics. 6th ed. Hong Kong: E \& FN Spon; 1998.

[7] Gao FP, Gu XY, Jeng DS, Teo HT. An experimental study for waveinduced instability of pipelines: The breakout of pipelines. Applied Ocean Research 2002;24:83-90.

[8] Gao FP, Gu XY, Jeng DS. Physical modeling of untrenched submarine pipeline instability. Ocean Engineering 2003;30:1283-304.

[9] Govardhan R, Williamson CHK. Modes of vortex formation and frequency response of a freely vibrating cylinder. Journal of Fluid Mechanics 2000;420:85-130.

[10] Grass AJ, Raven PWJ, Stuart RJ, Bray JA. The influence of boundary layer velocity gradients and bed proximity on vortex shedding from free spanning pipelines. Journal of Energy Resources Technology 1984;106: $70-8$.

[11] Hansen EA, Fredsøe J, Mao Y. Two-dimensional scour below pipelines. In: Proceedings of 5th international symposium on offshore mechanics and arctic engineering. Tokyo (Japan): ASME; 1986. p. 670-8.

[12] Herbich JB. Offshore Pipeline Design Elements. New York: Marcel Dekker Inc.; 1981.

[13] Jacobsen V, Bryndum MB, Nielsen R, Fines S. Cross flow vibrations of a pipe close to a rigid boundary. Transaction of ASME Journal of Energy Resources Technology 1984;106:451.

[14] Khalak A, Williamson CHK. Motions, forces and mode transitions in vortex induced vibrations at low mass-damping. Journal of Fluids and Structures 1999;13:813-51.

[15] Sarpkaya T, Isaacson M. Mechanics of wave forces of offshore structures. London: Van Nostrand Reinhold Company; 1981.

[16] Shen ZH, Liu YB, Li QP, Huang QH, Zhu FR. Experiments on interaction between current-induced vibration and scour of submarine pipelines on sandy bottom. China Ocean Engineering 2000;14:423-34.

[17] Sumer B, Jensen HR, Mao Y, Fredsøe J. Effects of lee-wake on scour below pipelines in currents. Journal of Waterway, Port, Coastal, and Ocean Engineering ASCE 1988;114:599-614.

[18] Sumer BM, Mao Y, Fredsøe J. Interaction between vibrating pipe and erodible bed. Journal of Waterway, Port, Coastal, and Ocean Engineering ASCE 1988;114:81-92.

[19] Sumer BM, Fredsøe J. The mechanics of scour in the marine environment. New Jersey: World Scientific Publishing Company; 2002. 
[20] Sumer BM, Truelsen C, Sichmann T, Fredsøe J. Onset of scour below pipelines and self-burial. Coastal Engineering 2001;42:313-35.

[21] Sumer BM, Whitehouse RJS, Torum A. Scour around coastal structures: A summary of recent research. Coastal Engineering 2001;44(2):153-90.

[22] Yang B, Gao FP, Wu YX. Numerical study of the occurrence of pipeline spanning under the influence of steady current. Ship Building of China 2005;46(Suppl.):221-6 [in Chinese].

[23] Yang B, Gao FP, Wu YX, Li DH. Experimental study on vortex-induced vibrations of submarine pipeline near seabed boundary in ocean currents. China Ocean Engineering 2006;20(1):113-21. 